\title{
The effect of shearing on the energy metabolism of the pregnant ewe
}

\author{
BY M. E. SYMONDS ${ }^{1}$, M. J. BRYANT ${ }^{2}$ AND M. A. LOMAX ${ }^{1}$ \\ Departments of ${ }^{1}$ Physiology \& Biochemistry and ${ }^{2}$ Agriculture, University of Reading, \\ Whiteknights, Reading RG6 $2 A J$
}

(Received 3 February 1986 - Accepted 16 June 1986)

\begin{abstract}
1. Metabolizable energy (ME) intakes, heat production, non-protein respiratory quotient (NPRQ) and the plasma concentrations of glucose, non-esterified fatty acids (NEFA), 3-hydroxybutyrate, insulin, growth hormone $(\mathrm{GH})$ and cortisol were measured in shorn and unshorn pregnant ewes.

2. Lamb birth-weight was $17 \%$ higher from shorn ewes despite similar ME intakes in the two groups. Shearing resulted in a significant decrease in the digestibility of dry matter and energy.

3. Both shorn and unshorn ewes were found to be in positive nitrogen balance and negative energy balance. Heat production was $28 \%$ higher in shorn ewes. This increase in heat production in the shorn group could be completely accounted for by an increase in the oxidation of fatty acids as measured using the NPRQ values.

4. Despite an apparent increase in the use of fat as an energy source there were no effects of shearing on the mean plasma concentrations of NEFA, 3-hydroxybutyrate, GH and cortisol.

5. Measurements made at $1 \mathrm{~h}$ intervals for $24 \mathrm{~h}$ indicated a tendency for the concentrations of glucose to be increased and insulin decreased in shorn ewes, particularly, between 6 and $11 \mathrm{~h}$ after feeding.

6. It is concluded that shearing pregnant ewes at 8 weeks before lambing results in a chronic increase in energy requirements which are met by oxidizing body fat depots. The cold stress induced by shearing may also inhibit insulin secretion resulting in increased plasma glucose concentrations. The effects of shearing on energy metabolism in the ewe are discussed in relation to the nutrient supply for the developing fetus.
\end{abstract}

Winter shearing of pregnant ewes during the final 10 weeks of gestation has been shown to result in a significant increase in lamb birth weight (LBW) (Rutter et al. 1971, 1972; Austin \& Young, 1977).

Voluntary food intake is stimulated in the shorn pregnant ewe (Austin \& Young, 1977; Maund, 1980) but the effect of shearing on LBW can still be observed when the food intake of shorn and unshorn animals is kept the same (Rutter et al. 1972). Thompson et al. (1982) have suggested that cold stress is the most likely factor influencing fetal development in shorn ewes: they observed a $15 \%$ increase in LBW when shorn ewes were maintained at $1-2^{\circ}$ and food intake was kept similar to that of a control group housed in a thermoneutral environment $\left(15^{\circ}\right)$. In a separate experiment, Thomspon et al. (1982) reported that a $2 \mathrm{~h}$ period of cold stress stimulated both maternal and fetal blood glucose concentrations. These observations led to the hypothesis that shearing increased the supply of glucose to the fetus resulting in an enhanced fetal growth rate, perhaps due to higher fetal insulin concentrations.

Short-term periods (less than $4 \mathrm{~d}$ ) of cold exposure are known to increase hepatic glucose production (Thompson et al. 1978), decrease insulin secretion (Sasaki \& Takahashi, 1980) and increase fat catabolism (Graham et al. 1958) in non-pregnant sheep. These metabolic adaptations are in response to the higher rate of nutrient oxidation necessary to meet the increase in heat production associated with cold exposure. The present study was therefore undertaken to examine the extent to which shearing pregnant ewes, housed in the cold environment of a normal British winter, results in long-term adaptation of energy metabolism previously observed in cold-exposed ruminants. Indirect open-circuit calorimeters were used to measure whole-body energy balance and estimate the contribution of body tissues to oxidative metabolism in shorn as compared with unshorn pregnant ewes. A preliminary report of this work has already been published (Symonds et al. 1985a). 


\section{EXPER I MENT A L}

Animals and diets

Eighteen pregnant Blue-faced Leicester $\times$ Swaledale ewes were paired with respect to ewe body-weight (range 66-94 kg) and housed individually at ambient temperature 10 weeks before lambing. Ewes were fed on a diet comprising barley concentrate $(\mathrm{g} / \mathrm{kg}$ fresh weight: 940 barley, 30 urea, 30 vitamins and minerals) and ammonia-treated straw in proportions $1: 3$ on a dry weight basis. During the final 8 weeks of pregnancy, diets were given to meet the requirements for maintenance and pregnancy (Agricultural Research Council, 1980), calculated at days 105, 119 and 133 of pregnancy in the unshorn ewes. Feed was given once daily at 08.30 hours and the refusals weighed. The mean metabolizable energy (ME) and nitrogen intakes over the complete experimental period were $9 \cdot 27 \mathrm{MJ} / \mathrm{d}$ and $19 \mathrm{~g} / \mathrm{d}$. The mean minimum and maximum daily temperatures recorded at 09.00 hours were $5 \cdot 1$ (SD 13.6) ${ }^{\circ}$ and $12 \cdot 6(\text { SD } 4 \cdot 2)^{\circ}$ respectively.

\section{Experimental design}

At approximately 8 weeks before lambing, one animal from each pair was shorn. During the period of 52-7 d before lambing, nine pairs of shorn and unshorn ewes were sequentially placed in metabolism crates inside two individual indirect open-circuit respiration chambers for a $5 \mathrm{~d}$ period. During this time a total collection of faeces and urine was made in order to measure $\mathrm{ME}$ intake and $\mathrm{N}$ balance, as well as recording the animal's heat production using measurements of oxygen consumption, and carbon dioxide and methane production.

At approximately $19 \mathrm{~d}$ before lambing, catheters were inserted into a jugular vein in eight shorn and seven unshorn sheep and on the following day blood samples $(10 \mathrm{ml})$ were taken at $1 \mathrm{~h}$ intervals for $24 \mathrm{~h}$. Plasma was collected and stored at $-20^{\circ}$.

\section{Experimental procedures}

The design and equipment of the open-circuit respiration apparatus was essentially as described by Cammell et al. (1981) with the addition that all measurements and operations were continually monitored and controlled using a microcomputer system as described by Symonds et al. (1985b).

A $5 \mathrm{~d}$ period was adopted to measure total energy balance as this was the minimum period over which urine and faecal collection could be representatively made, and it increased the accuracy of estimating heat production. Animals were placed in mock chambers for at least $2 \mathrm{~d}$ before each $5 \mathrm{~d}$ balance period to allow acclimatization to the enclosed space of the open-circuit respiration chambers. Subsequent studies demonstrated there was no difference in the accuracy of estimating energy balance between this procedure and the use of a $7 \mathrm{~d}$ period of faeces and urine collection followed by a $2 \mathrm{~d}$ period of measuring heat production (Eayres et al. 1985). The mean temperature inside the calorimeter was 11.9 (SD 0.9) ${ }^{\circ}$ during the experimental period.

Non-protein respiratory quotient (NPRQ) and heat production were calculated using the measured values for $\mathrm{O}_{2}$ consumption, $\mathrm{CO}_{2}$ and $\mathrm{CH}_{4}$ production and urinary $\mathrm{N}$ excretion (Brouwer, 1965). This also enabled the calculation of the contribution of fat, carbohydrate and protein metabolism to whole-body heat production as described by Brody (1945). The respiration chambers were calibrated by burning a known amount of butane gas in the chamber: this method gave a mean recovery (\%) of 96.1 (SE 0.9) and 90.8 (SE 1.3) (n 8) with respect to theoretical values for $\mathrm{CO}_{2}$ and $\mathrm{O}_{2}$ respectively. The coefficient of variation for measurement of daily heat production over each $5 \mathrm{~d}$ period was $5 \cdot 7 \pm 0 \cdot 7 \%(n 18)$. 


\section{Laboratory procedures}

Samples of food, refusals and fresh excreta were analysed for $\mathrm{N}$ by the micro-Kjeldahl method; energy content was determined by use of an adiabatic bomb calorimeter, all samples first being freeze-dried.

The concentration of glucose in plasma was measured using the enzyme glucose oxidase (EC 1.1.3.4; Bergmeyer \& Bernt, 1974), 3-hydroxybutyrate by the enzymic method of Williamson et al. (1962) and non-esterified fatty acids (NEFA) by the Wako NEFAC test (Alpha Laboratories Ltd, Eastleigh, Hampshire). Plasma concentrations of insulin and growth hormone $(\mathrm{GH})$ were measured using a 'double-antibody' radioimmunoassay. The method for insulin was based on that described by Tindal et al. (1978) using bovine insulin for standards and guinea-pig antiserum to insulin (Wellcome Reagents Ltd) and donkey antiserum to guinea-pig $\gamma$-globulin (Guildhay Antisera, University of Surrey, Guildford, Surrey). The interassay coefficient of variation for insulin analysis was $8.9 \%(n 6)$. GH was measured by a method similar to that outlined by Hart et al. (1975) using bovine GH for iodination and standards (NIH-GH-B18; Endocrinology Study Section, National Institute of Arthritis and Metabolism and Digestive Diseases, Bethesda, Maryland), a rabbit antiovine GH antibody (a gift from Dr J. M. Forbes, Department of Animal Physiology and Nutrition, University of Leeds, Leeds) and donkey antiserum to rabbit $\gamma$-globulin (Guildhay Antisera). The anti-ovine GH antibody showed negligible cross-reaction to other hypophyseal hormones (Driver et al. 1979) and the coefficient of variation for GH analysis was $22.5 \%(n 10)$. The concentration of cortisol in plasma was measured after incubation of plasma samples, cortisol standards (Sigma Chemical Company Ltd, Poole, Dorset) and $\left[1,2,6,7-{ }^{3} \mathrm{H}\right]$ cortisol (Amersham International plc, Amersham, Bucks) with a specific antibody (code no. R22/23, supplied by Dr B. J. A. Furr, ICI Pharmaceuticals Division, Macclesfield, Cheshire) made up in a diluent buffer of $0.2 \mathrm{M}$-sodium acetate and $1 \mathrm{~g}$ gelatin/1 at $\mathrm{pH}$ 4.0 (Dr Glenys Bloomfield, Animal and Grassland Research Institute, Shinfield, Reading, personal communication). The interassay coefficient of variation for cortisol analysis was $4.8 \%(n 4)$.

\section{Statistical analysis}

Statistical analysis of the energy balance data was performed using a Student's paired $t$ test (shorn $v$. unshorn). Further changes in the relative contribution of carbohydrate, fat and protein oxidation to total heat production and measurements of plasma metabolites and hormones were assessed by a Student's $t$ test following the removal of sheep which only produced single lambs (shorn $n 2$; unshorn $n 3$ ).

\section{RESULTS}

$L B W$, ewe live weight and dry matter $(D M)$ intake

Three of the nine unshorn ewes each produced singles, twins and triplets and of the nine shorn sheep two each had singles and triplets and five bore twins. A Student's $t$ test demonstrated that shearing resulted in a significant increase in LBW (shorn 4.35 (SEM $0 \cdot 15$ ) $\mathrm{kg}, n 18$; unshorn 3.74 (SEM 0.22$) \mathrm{kg}, n 18 ; P<0.05$ ). From Table 1 it can be seen that this effect was achieved even though there were no differences in ewe live weight between the shorn and unshorn groups over the final $56 \mathrm{~d}$ of pregnancy. There was also a significant loss in body-condition score during the final $34 \mathrm{~d}$ of pregnancy in both shorn $(P<0.001)$ and unshorn $(P<0.01)$ animals. 
Table 1. Mean dry matter (DM) intake, apparent DM digestibility (DM DIG), ewe live weight $(W)$ and body condition score $(B C S)$ for unshorn and shorn pregnant ewes during the final $56 \mathrm{~d}$ of pregnancy

(Values are means with their standard errors)

\begin{tabular}{|c|c|c|c|c|}
\hline & \multicolumn{2}{|c|}{ Shorn $(n 9)$} & \multicolumn{2}{|c|}{ Unshorn $(n 9)$} \\
\hline & Mean & SEM & Mean & SEM \\
\hline DM intake $(\mathrm{kg})$ & 1.02 & 0.08 & 0.91 & 0.03 \\
\hline DM DIG & $0.64 * *$ & 0.015 & 0.69 & 0.018 \\
\hline \multicolumn{5}{|l|}{ W (kg): } \\
\hline $56 \mathrm{~d}$ before lambing & 77.9 & $2 \cdot 5$ & 77.5 & $2 \cdot 2$ \\
\hline $17 \mathrm{~d}$ before lambing & 77.7 & $2 \cdot 9$ & 77.2 & $2 \cdot 2$ \\
\hline Post-lambing & $69 \cdot 3$ & 1.8 & $68 \cdot 2$ & 2.6 \\
\hline \multicolumn{5}{|l|}{ BCS: } \\
\hline $34 \mathrm{~d}$ before lambing & $2 \cdot 9^{\mathrm{a}}$ & $0 \cdot 1$ & $2 \cdot 9^{\mathrm{a}}$ & $0 \cdot 2$ \\
\hline At lambing & $2 \cdot 1^{\mathrm{c}}$ & $0 \cdot 1$ & $2 \cdot 1^{b}$ & 0.2 \\
\hline
\end{tabular}

${ }^{* *} P<0 \cdot 01$.

a,b,cBCS values in the same column with different subscript letters were significantly different (paired $t$ test): ${ }^{\text {ab }} P<0.01,{ }^{\text {ac }} P<0.001$.

Table 2. Gross energy $(G E)$ intake, apparent $G E$ digestibility $(G E D I G)$, metabolizable energy $(M E)$ intake, heat production $(H)$, energy from body tissue $(B T)$ and nitrogen balance in unshorn and shorn pregnant ewes

(Values are means with their standard errors)

\begin{tabular}{|c|c|c|c|c|}
\hline & \multicolumn{2}{|c|}{ Shorn $(n 9)$} & \multicolumn{2}{|c|}{ Unshorn $(n 9)$} \\
\hline & Mean & SEM & Mean & SEM \\
\hline GE intake $(\mathrm{MJ} / \mathrm{d})$ & $19 \cdot 0$ & 1.56 & $16 \cdot 8$ & 0.64 \\
\hline GE DIG & $0.62^{* *}$ & 0.016 & 0.67 & 0.019 \\
\hline ME intake (MJ/d) & 10.04 & 0.89 & 9.95 & 0.47 \\
\hline $\mathrm{H}(\mathrm{MJ} / \mathrm{d})$ & $15 \cdot 45^{* * *}$ & 0.52 & $12 \cdot 10$ & 0.52 \\
\hline $\mathrm{BT} \dagger(\mathrm{MJ} / \mathrm{d})$ & $5 \cdot 30^{*}$ & 0.88 & $2 \cdot 39$ & 0.46 \\
\hline $\mathrm{N}$ balance $(\mathrm{g} / \mathrm{d})$ & $5 \cdot 5$ & $1 \cdot 1$ & $6 \cdot 4$ & 0.8 \\
\hline
\end{tabular}

$* P<0.05,{ }^{* *} P<0.01, * * * P<0.001$.

$\lceil\mathrm{BT}=$ (heat production + gravid uterus accretion) $-\mathrm{ME}$ intake. Gravid uterus accretion calculated from Tissier et al. (1980): shorn $0 \cdot 25$, unshorn $0 \cdot 24 \mathrm{MJ} / \mathrm{d}$.

DM intake was not significantly different between groups (Table 1) although shorn animals tended to have slightly higher values due to a greater intake of ammonia-treated straw. The apparent digestibility of DM was lower $(P<0.01)$ in the shorn group.

\section{Energy and $N$ balance}

Table 2 illustrates that all ewes were in positive $\mathbf{N}$ balance. The gross energy (GE) intake appeared to be greater in the shorn group but the value for apparent digestibility of $\mathrm{GE}$ was significantly lower $(P<0.01)$ with the result that ME intake was the same for both groups. Heat production was $28 \%$ greater in shorn as compared with unshorn animals. An estimate of energy apparently derived from body tissues was made by subtracting the ME intake from heat production (plus an allowance for the amount of energy which was stored 


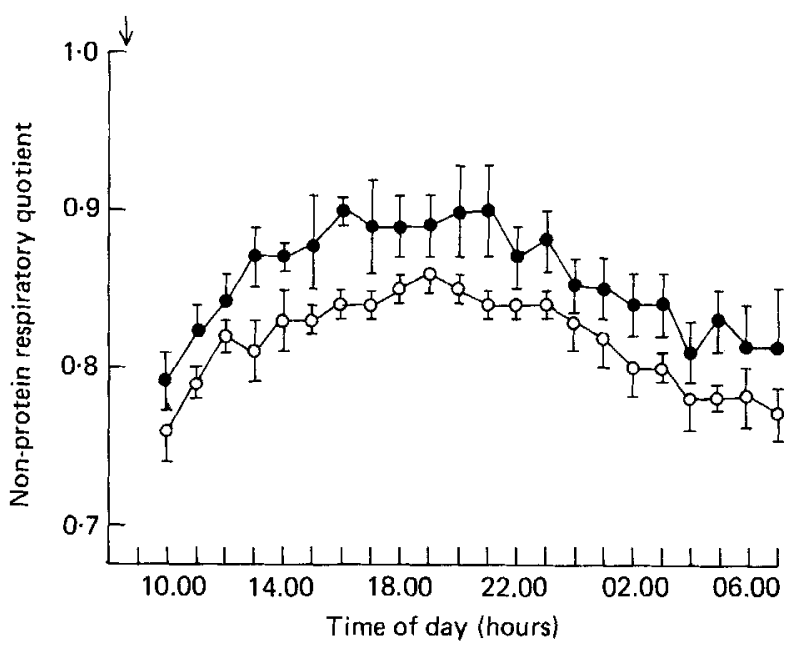

Fig. 1. Hourly non-protein respiratory quotient of shorn $(O)(n 7)$ and unshorn $(O)(n 6)$ twin- and triplet-bearing sheep. Values are means, with their standard errors represented by vertical bars. $\downarrow$, Fed.

Table 3. The effect of shearing on non-protein respiratory quotient $(N P R Q)$ and on the relative contribution $\left(M J / \mathrm{kg}\right.$ body-weight ${ }^{0.75}$ per d) of carbohydrate, fat and protein oxidation to total heat production $(H)$ in twin- and triplet-bearing pregnant ewes

(Values are means with their standard errors)

\begin{tabular}{llllll}
\hline & \multicolumn{2}{c}{ Shorn $(n 7)$} & & \multicolumn{2}{c}{ Unshorn $(n$ 6) } \\
\cline { 2 - 3 } & Mean & SEM & & Mean & SEM \\
\hline Total H & $0.588^{*}$ & 0.022 & & 0.498 & 0.020 \\
NPRQ & $0.81 \dagger$ & 0.01 & & 0.84 & 0.01 \\
H due to: & & & & \\
$\quad$ Carbohydrate oxidation & 0.205 & 0.021 & & 0.229 & 0.026 \\
$\quad$ Fat oxidation & $0.352^{*}$ & 0.024 & 0.245 & 0.025 \\
$\quad$ Protein oxidation & 0.031 & 0.003 & 0.024 & 0.004 \\
\hline
\end{tabular}

Mean values were significantly different (Student's $t$ test): $* P<0 \cdot 05, \dagger P=0 \cdot 08$.

in uterine and fetal tissues during the period that these measurements were made). This calculation indicated that both groups were mobilizing body tissue and that this value was significantly greater $(P<0.05)$ in the shorn ewes.

$N P R Q$ and the relative contribution of carbohydrate, fat and protein to total heat production

In Fig. 1 it can be seen that in both shorn and unshorn groups there was a marked daily variation in NPRQ which was at a minimum immediately post feeding and reached maximum values between 15.00 and 23.00 hours before gradually decreasing through the remainder of the night. Throughout this $22 \mathrm{~h}$ period the NPRQ was higher in the unshorn group. This is confirmed in Table 3 in which the mean daily NPRQ was greater $(P=0.08)$ in the unshorn group. 
Table 4. Mean plasma concentrations of glucose, non-esterified fatty acids (NEFA), 3hydroxybutyrate, growth hormone $(G H)$, insulin and cortisol in twin- four shorn and three unshorn) and triplet- (one shorn and two unshorn) bearing pregnant ewes

(Values are means with their standard errors)

\begin{tabular}{lccccc}
\hline & \multicolumn{2}{c}{ Shorn $(n$ 5) } & & \multicolumn{2}{c}{ Unshorn $(n$ 5) } \\
\cline { 2 - 3 } & Mean & SEM & & Mean & SEM \\
\hline Glucose (mM) & 2.92 & 0.34 & 2.68 & 0.27 \\
NEFA (mM) & 0.57 & 0.12 & & 0.61 & 0.10 \\
3-hydroxybutyrate (mM) & 0.87 & 0.40 & & 0.95 & 0.48 \\
GH (ng/ml) & 15.51 & 3.34 & & 12.64 & 2.56 \\
Insulin (ng/ml) & $0.25 \dagger$ & 0.05 & & 0.44 & 0.08 \\
Cortisol (ng/ml) & 6.3 & 0.04 & & 7.9 & 2.5 \\
\hline
\end{tabular}

Mean value was significantly different (Student's $t$ test): $\uparrow P=0 \cdot 07$.

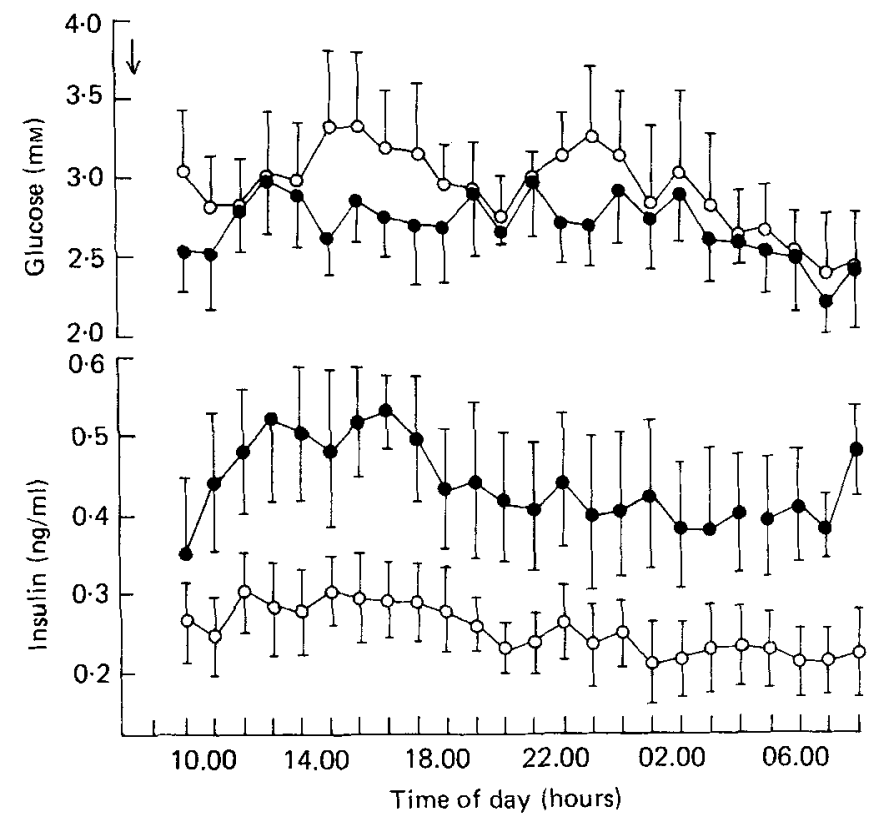

Fig. 2. Hourly plasma glucose and insulin concentrations in shorn $(O)(n$ 5) and unshorn (O) (n 5) twinand triplet-bearing sheep. Values are means, with their standard errors represented by vertical bars. $\downarrow$, Fed.

A comparison of the relative contribution of carbohydrate, fat and protein to total heat production (Table 3) in twin- and triplet-bearing animals demonstrated that shearing had no effect on carbohydrate or protein metabolism. However, the increased heat production observed on shearing was completely accounted for by an increase in fat catabolism.

Plasma metabolite and hormone concentration

Shearing had no effect on the mean plasma concentration of NEFA, 3-hydroxybutyrate, $\mathrm{GH}$ or cortisol over a $24 \mathrm{~h}$ period (Table 4 ). Shorn animals did have a lower mean plasma 
concentration of insulin $(P=0.07)$ and a higher mean plasma concentration of glucose. The effects of shearing on insulin and glucose levels are more apparent from the $24 \mathrm{~h}$ profiles of plasma glucose and insulin concentrations (Fig. 2). This shows that throughout the $24 \mathrm{~h}$ sampling period the trend was for plasma glucose to be higher and plasma insulin concentrations lower in the shorn ewes. This effect was most marked between 14.00 and 19.00 hours, i.e. $6-11 \mathrm{~h}$ after feeding.

\section{DISCUSSION \\ $L B W$ and feed intake}

The present study is in accord with previously published observations that shearing pregnant ewes during the final 10 weeks of pregnancy results in a significant increase in LBW (Rutter et al. 1971, 1972; Adalsteinsson, 1972; Austin \& Young, 1977; Maund, 1980; Morgan \& Broadbent, 1980). Furthermore, we have confirmed the report by Rutter $e t$ al . (1972) that the increase in LBW occurs independently of any effects of shearing on voluntary food intake: in our experiment the ME intake was similar in both shorn and unshorn groups. There was, however, a slightly higher DM intake in shorn ewes, accompanied by a significant decrease in the apparent digestibility of both DM and GE. These observations are not unexpected since it is well established that prolonged exposure of non-pregnant sheep to a cold environment $\left(2-5^{\circ}\right)$ results in a depression of DM and GE digestibility in association with an increased passage of digesta through the reticulo-rumen (Westra \& Christopherson, 1976; Kennedy et al. 1977).

\section{The contribution of body tissues to energy metabolism in the ewe}

Shearing resulted in a major increase in energy requirements as demonstrated by the $28 \%$ increase in heat production when compared with unshorn controls. Graham et al. (1958) observed that in shorn wethers, heat production increased linearly with a decrease in environmental temperature below $23^{\circ}$ irrespective of feeding level. The pregnant sheep in the present study were exposed to an average temperature of $11^{\circ}$ and therefore it seems likely that the increased heat production observed on shearing was the result of metabolic adaptations to a cold environment although this difference may be an underestimate as the mean temperature in the calorimeter chamber was warmer than ambient temperature.

The results of the whole-animal energy balance trial demonstrated that both shorn and unshorn ewes were utilizing body tissues. The pregnant ewe may be expected to draw on body tissues to provide an endogenous supply of energy during the final 8 weeks of pregnancy, although in well-fed sheep the loss of weight from maternal tissues should be more than offset by the increase in weight of the conceptus (Russell, 1984). However, in the present study ewe weight did not change during the final $56 \mathrm{~d}$ of pregnancy and body condition score decreased during this period. It is likely that both groups of ewes were deriving significant amounts of energy from body tissues because the intake of straw DM was lower than that predicted.

It was apparent that the shorn ewes were deriving significantly more energy from maternal tissues than unshorn controls. In addition the increased heat production observed on shearing was almost totally accounted for by an increase in energy apparently derived from the oxidation of fat. This agrees with the studies of Graham et al. (1958) who similarly reported that the rise in heat production of cold-exposed non-pregnant sheep was the result of increased fat catabolism, with no change in either protein or carbohydrate oxidation. The plasma concentrations of NEFA and 3-hydroxybutyrate were similar to those reported in other studies for ewes at this stage of pregnancy (e.g. Pethick \& Lindsay, 1982; Pethick et al. 1983). It is, however, surprising that the increase in fat oxidation observed on shearing did not result in any change in plasma NEFA concentrations. Several groups have 
demonstrated a linear relation between plasma NEFA concentrations and NEFA turnover and oxidation rates in fed and fasted pregnant (Pethick et al. 1983) and non-pregnant sheep (Annison et al. 1967). Our results agree with the proposal made by Graham \& Phillips (1981) that the relation between plasma concentration and turnover rate of NEFA may change following exposure to cold for an extended period of time. This study further suggests that shorn ewes are better adapted to utilize NEFA without exhibiting the high plasma NEFA and ketone body concentrations that are found in animals at risk from pregnancy toxaemia (Pethick et al. 1983).

A possible endocrine mechanism responsible for this cold adaptation may be an increase in thyroid hormone secretion, since Westra \& Christopherson (1976) have found elevated levels of circulating thyroid hormones during cold exposure of non-pregnant sheep. Increased plasma concentrations of $\mathrm{GH}$ have also been implicated in the mobilization of body fat in pregnant ewes (Hove \& Blom, 1976) and in cold-exposed cattle (Olsen \& Trenkle, 1973). However, there was no difference in plasma GH concentrations between shorn and unshorn ewes. Alternatively it has been demonstrated that the plasma concentrations of catecholamines are increased during cold exposure of non-pregnant sheep (Christopherson et al. 1978) and it is possible that the sympathetic nervous system may have an important role in controlling fat metabolism in the shorn pregnant ewe.

\section{The effect of shearing on blood glucose homeostasis}

The utilization of glucose by utero-placental and fetal tissues may account for at least $35 \%$ of maternal glucose production (Hay et al. 1983) during the last few weeks of pregnancy in sheep. The hourly measurements of plasma glucose concentration on day 127 of pregnancy showed that the average maternal levels were higher in the shorn animals throughout the day despite a presumed greater requirement for glucose by the heavier conceptus. This suggests that the shorn ewes are also better adapted to meet the increased glucose requirements of late pregnancy.

Several studies have demonstrated that cold exposure of pregnant sheep results in raised concentrations of glucose in plasma (Mellor et al. 1975; Thompson et al. 1982). This effect may be due to an increase in hepatic glucose output (Thompson et al. 1978), possibly as a result of elevated plasma cortisol concentrations (Bassett \& Alexander, 1971). In the present study no difference was observed in the plasma concentrations of cortisol between shorn and unshorn groups. However, plasma insulin concentrations were lower in the shorn animals, particularly during the period of $6-11 \mathrm{~h}$ after feeding when plasma glucose concentrations were higher in the shorn group. Shearing may therefore result in a long-term inhibition of insulin secretion similar to that observed in non-pregnant sheep exposed to low environmental temperatures (Sasaki \& Takahashi, 1980). However, these results should be interpreted with caution because Weekes et al. (1983) have shown that cold-exposed, non-pregnant sheep exhibit an enhanced responsiveness to insulin despite the decrease in secretory rate.

Thompson et al. (1982) have proposed the hypothesis that the increased LBW in shorn ewes is due to an increased supply of glucose to the fetus which may then stimulate fetal insulin concentrations and fetal growth. The results of the present study support this hypothesis to the extent that maternal plasma glucose concentrations are raised 5 weeks after shearing and may therefore be implicated in the enhancement of LBW.

It is concluded that winter shearing of pregnant ewes results in long-term metabolic adaptation to a cold environment which is beneficial to both ewe and fetus. The ewes appear to be able to utilize body fat to meet the increased energy expenditure associated with cold exposure, without apparent risks from clinical ketosis. Furthermore, fetal growth is enhanced perhaps as a result of these metabolic adaptations. 
M.E.S. acknowledges the support of a MAFF studentship. This work was also supported by a grant from the AFRC.

\section{REFERENCES}

Adalsteinsson, S. (1972). Acta Agriculturae Scandinavica 22, 93-96.

Agricultural Research Council (1980). The Nutrient Requirements of Ruminant Livestock, pp. 115-119. Slough: Commonwealth Agricultural Bureaux.

Annison, E. F., Linzell, J. L., Fazakerley, S. \& Nichols, B. W. (1967). Biochemical Journal 102, $637-747$.

Austin, A. R. \& Young, N. E. (1977). Veterinary Record 100, 527-529.

Bassett, J. M. \& Alexander, G. (1971). Biology of the Neonate 17, 112-125.

Bergmeyer, H. V. \& Bernt, E. (1974). In Methods of Enzymatic Analysis, vol. 3, pp. 1205-1215. [H. V. Bergmeyer, editor]. Weinheim: Verlag Chemie.

Brody, S. (1945). Bioenergetics and Growth, pp. 307-313. New York: Hafner Publishing Co.

Brouwer, E. (1965). In Energy Metabolism. Publication of the European Association for Animal Production no. 11, pp. 441-443 [K. L. Blaxter, editor]. London: Academic Press.

Cammell, S. B., Beever, D. E., Skeiton, K. V. \& Spooner, M. C. (1981). Laboratory Practice 30, 115-119.

Christopherson, R. J., Thompson, J. R., Hammond, V. A. \& Hills, G. A. (1978). Canadian Journal of Physiology and Pharmacology 56, 490-496.

Driver, P., Forbes, J. M. \& Scanes, C. G. (1979). Journal of Physiology 290, 399-411.

Eayres, S. M., Lomax, M. A. \& Bryant, M. J. (1985). Proceedings of the Nutrition Society 44, 62 A.

Graham, A. D. \& Phillips, G. D. (1981). Canadian Journal of Animal Science 61, 919-924.

Graham, N. McC., Wainman, F. W., Blaxter, K. L. \& Armstrong, D. G. (1958). Journal of Agricultural Science 52, 13-24.

Hart, I. C., Flux, D. S., Andrews, P. \& McNeilly, A. S. (1975). Hormone and Metabolic Research 7, 35-40.

Hay, W. W., Sparks, J. W., Wilkening, R. B., Battaglia, F. C. \& Meschia, G. (1983). American Journal of Physiology 245, E347-E350.

Hove, K. \& Blom, A. K. (1976). Acta Endocrinologica 82, 544-552.

Kennedy, P. M., Young, B. A. \& Christopherson, R. J. (1977). Journal of Animal Science 45, $1084-1090$.

Maund, B. A. (1980). Animal Production 30, 481, Abstr.

Mellor, D. J., Slater, J. S. \& Matheson, I. C. (1975). Research in Veterinary Science 18, 219-221.

Morgan, H. \& Broadbent, J. S. (1980). Animal Production 30, 476, Abstr.

Olsen, J. D. \& Trenkle, A. (1973). American Journal of Veterinary Research 34, 747-751.

Pethick, D. W. \& Lindsay, D. B. (1982). British Journal of Nutrition 48, 549-563.

Pethick, D. W., Lindsay, D. B., Barker, P. J. \& Northrop, A. J. (1983). British Journal of Nutrition 49, $129-142$.

Russell, A. J. F. (1984). Livestock Production Science 11, $429-436$.

Rutter, W., Laird, T. R. \& Broadbent, P. J. (1971). Animal Production 13, 329-336.

Rutter, W., Laird, T. R. \& Broadbent, P. J. (1972). Animal Production 14, 127-130.

Sasaki, Y. \& Takahashi, H. (1980). Journal of Physiology 306, 323-335.

Symonds, M. E., Bryant, M. J. \& Lomax, M. A. (1985a). Proceedings of the Nutrition Society 44, 53A.

Symonds, M. E., Bryant, M. J. \& Lomax, M. A. (1985b). In Substrate and Energy Metabolism in Man, p. A22. [J. S. Garrow and D. Halliday, editors]. London: John Libbey.

Tindal, J. S., Knaggs, G. S., Hart, I. C. \& Blake, L. A. (1978). Journal of Endocrinology 76, 333-346.

Thompson, G. E., Bassett, J. M. \& Bell, A. E. W. (1978). British Journal of Nutrition 39, 219-226.

Thompson, G. E., Bassett, J. M., Samson, D. E. \& Slee, J. (1982). British Journal of Nutrition 48, 59-64.

Tissier, M., Theriez, M., Purroy, A. \& Brelurut, A. (1980). In Energy Metabolism, pp. 329-33. [L. E. Mount, editor]. London: Butterworths.

Weeks, T. E. C., Sasaki, Y. \& Tsuda, T. (1983). American Journal of Physiology 244, E335-E345.

Westra, R. \& Christopherson, R. J. (1976). Canadian Journal of Animal Science 56, 699-708.

Williamson, D. H., Mellanby, J. \& Krebs, H. A. (1962). Biochemical Journal 82, 90-96. 